\title{
Good Practice in Public Health: Thinking About the Economics of Complex Emergencies
}

\author{
Danielle Deboutte
}

\section{Abstract}

Emergency public health action is often faced with severe constraints. Limited resources are available to respond to sometimes-immense initial requirements and competing needs. Ethical decisions in public health can only be made when the decision-maker understands the arguments for and against, and decides in the light of this knowledge. Emergency budgets are not unlimited, have alternative possible uses, and can easily be wasted. Yet many aid workers find it impossible or unethical to consider the cost of emergency aid.

This paper proposes to consider the use of economic methods in three ways:

1- to assist with rational decision-making.

2- to offer a tool for continuously monitoring interventions.

3- to enable programme evaluation in terms of cost-effectiveness.

\section{Résumé}

L'action sanitaire d'urgence rencontre souvent des contraintes très sévères. Les ressources disponibles sont limitées pour faire face a des besoins initiaux souvent immenses et concurrents. Les décisions de nature éthique en matière de santé publiquene peuventêtreprises quequand les décideurs comprennent à fond la totalitédes arguments pour et contre, et arrêtent une position éclairée par cette connaissance. Les budgets d'urgence ne sont pas illimités. Ils ont des possibilités d'utilisation différentes, et peuvent conséquemment être facilement gaspillés. Et pourtant de nombreux

Danielle Deboutte has a Masters degree in public health from London School of Hygiene and Tropical Medicine, and is currently employed by the World Health Organization as a short term professional in the Department of Emergency and Humanitarian Action. intervenants considèrent éthiquement questionnable une position consistant a scruter attentivement le coût de l'aide d'urgence. Cet article propose de considérer la mise a profit de méthodes économiques selon trois avenues:

1-l'appuiapportéà des prises de décision rationnelles;

2-l'apport d'un outil servant à assurer un suivi constant et fiable des interventions;

3- la possibilité de formuler une évaluation des programmes en termes de rendement.

\section{Is Economics Relevant in Emergencies?}

Humanitarian action in complex emergency situations is fraught with uncertainty. At the onset, it is necessary to provide immediate relief for survival, while access may be limited by environmental and security constraints. Plans will rely on rapid assessments and standard approaches. Under these circumstances, resources are easily wasted. Yet many aid workers consider it impossible and in any case unethical to consider the cost of emergency aid.

Programme monitoring and evaluation are complicated by unpredictable events, making it hard to tease out programme effects from incidental occurrences. Evaluation of the early objective to preserve lives rarely considers a comparison of operational cost. Long-term evaluation needs explicit objectives and a set of measurable indicators. An estimate of the cost to achieve a certain output would be relevant for both planning and evaluation.

The public health sector has long recognised, at least in principle, the need to make optimal use of limited resources. Public health professionals are responsible for decisions on how to address a range of population needs related to health care. Decisions on the provision of services are increasingly guided by the availability of effective interventions. The extent of the budget allocated will depend on the size and seriousness of a problem, and on the cost of the intervention. In the management of humanitarian emergency situations, the limitation of resources may be even more pronounced, sometimes in the context of immense initial requirements. Relief programme decisions should aim to maximise health gain within available resources, and economic analysis has a role in this goal.

Health economics applies theories, tools and concepts of economics to the health sector. It looks at allocation of resources within the economy to the health care system, and the distribution of these resources to different activities and individuals. ${ }^{1}$ Introducing health economics in the public health management of emergencies could be of use in three ways:

1. to assist with rational decision making.

2. to offer a tool for continuously monitoring the effectiveness of interventions.

3. toenable programme evaluation in terms of cost-effectiveness.

\section{Making Rational Decisions}

Following an emergency, decisions are typically made by donors about the magnitude of funding and often about the type of programme to be implemented in a particular place (earmarked funds). These decisions are guided by requests from humanitarian agencies, of which some are implementing partners, and by the governments of affected countries. In the context of development, governments of implementing countries are considered to be the best judges of their nation's needs. In emergency situations, complicated by civil 
uprising, this assumption may only hold for part of the population. An impartialneeds assessmentbecomes mandatory.

Control of an acute emergency is achieved by provision of effective care, including basic needs such as water, sanitation and food if needed, to as many survivors as possible in an equitable way. Decisions on who provides relief aid and how it should be delivered are usually made from a purely pragmatic point of view. In the advent of an emergency, numerous relief agencies compete for limited funding.

Operational humanitarian agencies should be unbiased advocates of the health and human rights of the population they serve. The taxpayer assumes that funding for humanitarian agencies is related to the needs of the beneficiary population. With no clear criteria to evaluate efficiency and cost-effectiveness of emergency interventions, funding of agencies and thus their own survival largely depend on field visibility (i.e. attraction of media) and the image this creates vis-à-vis potential donors. In this context, economic analysis can provide rational methods for decision making, which should result in better outcomes.

\section{Offer a Tool to Monitor Interventions}

If programmes are effective, the general health and nutrition situation of the population should ameliorate and stabilise, at least in comparison to what would happen without the intervention. When essential needs are not or insufficiently addressed, theremay be a reduction in the overall effect of the humanitarian intervention and a lag in service delivery. Measuring inputs and outcomes in one sector may indirectly point to shortcomings in another. Overlooking the link between nutrition and communicable diseases can lead to high death rates in malnourished individuals with an infection. At the time of an epidemic, adequate feeding and disease management, including correct sanitary measures will have better results than each intervention on its own. ${ }^{2}$
The course of humanitarian emergencies cannotbe predicted. The evolution of the security situation and ease of access to an area can influence the nutritional and health status of the population. Existing programmes oftenneed to be modified, and new interventions maybe required. To provide an efficient response, the data obtained by immunisation and nutrition surveys should be complemented with routine data from health system surveillance. The epidemiological findings could be compared to expenditure on food, medicine and other programmes. This comparison would be a step towards recognising the level of interaction between the various harmful factors in a complex emergency, and finding ways to compose and maintain a balanced package of services. Expenditure on medicine for curative purposes may be of littlebenefit to a hungry population of internally displaced persons if access to health services is limited. Under those circumstances, it might be more useful in the short run to distribute food and seeds for planting. The net effect of using part of the medicine budget for preventive services will be better health. ${ }^{3}$

\section{Enable Programme Evaluation in Terms of Cost-Effectiveness}

The evaluation of emergency assistance to Rwanda (5 volumes) 4 includes 10 pages that deal with the financial cost of the operation. It is noted that it was not possible to break down the overall known allocations of USD 1.29 billion. At the same time, donors want value for money, but are unwilling to separately finance programme evaluations. With support from international agencies such as the World Health Organization, prospective data collection could be tested in a limited number of settings. The aim would be to match data on the cost of programmes and programmeelements with outcomes in terms of vital population statistics (morbidity, mortality and malnutrition).

Relief workers sometimes argue that it would be unethical to apply economic analysis in emergencies. This argument is based on the same reasoning used to discredit health economics in general, i.e. that human life has no price. In reply it can be pointed out that it may not be universally possible to say what should be the value of a life, but within a given budget we should strive to preserve as many lives, and reduce as much morbidity, as possible. In any case, finite values are placed on emergency action in the way every budget is set. It is important to remember that:

- funds used for humanitarian relief operations have alternative possible uses.

- every humanitarian operation is determined by the size of its budget.

- the collective budget available for a humanitarian operation does not perse reflect the needs of the population.

- within a given relief setting, there will be competing options for the use of funds.

- an accurate estimate of population needs with ranking order of importance, would be useful - without ranking of needs, budget allocation depends on supplier preference.

-if the cost to satisfy the different population needs can be calculated, it should be possible to draw up a budget to cover these needs - without this exercise, budgets are based on guesses at best and emotions at worst.

In public health care, the issue is not the ethics of behaviour, but the ethics of decision making. Adecision is made in an ethical way when the decisionmaker understands the arguments for or against a decision, and decides in the light of this knowledge. In almost all cases, arguments for and against the issue must be weighed. The concept of "do no harm" conflicts with the notion to "do more good", since some people will beharmed by decisions that achieve a general improvement in health. Duty to the individual may conflict with duty to the people, and helping more people may conflict with helping those individuals most in need. Healtheconomics will help to make the optimal choice to help the greatestnumber of peoplein the most efficient way possible on the basis of available data. 


\section{Ways in Which Health Economics Can Be Used}

It is neither possible nor desirable to set a fixed level of expenditure for a particular type of intervention. However, by deconstructing an operation into all of its elements (e.g. cost of goods, personnel, and transport) it is possible to arrive at an approximate cost for a defined project. It should also be possible to predict thenumber of beneficiaries, provided the target population and the extent of the emergency are known. This kind of baseline assessment can be used as a tool for budgeting, and for evaluating the outcome of an intervention, if epidemiological data on the beneficiary population are recorded. In fact, some agencies have started to move towards this approach.

A comparison of strategies to manage cholera outbreaks illustrates how health economics can be used in making policy decisions in emergencies. Costeffectiveness analysis indicated that stock piling of treatment kits in the area was more cost-effective than vaccination. ${ }^{5}$ Another study by MSF in Nigeria ${ }^{6}$ showed that meningitis vaccination at the height of an epidemic was extremely costly per case averted, compared to correct case management. Neither of these examples should be used to discredit vaccination as a way to avoid disease. Instead they indicate the importance of correctly timing interventions to obtain maximum benefit at a given cost.

Analysis of surveillance data can give an indication of the relative importance over time of different interventions in one particular setting, and of the scope for expanding one programme and reducing another. Health economics provides tools to calculate the marginal cost, or the incremental unit cost (a measure of the resources associated with a small incremental change in output $)^{7}$ of variations in programme output. At field level, direct accounting methods can be used. Statistical modelling techniques at headquarters level, could facilitate donor decisions on budget size for different programmes in the same emergency zone.

\section{Good Public Health Practice in Emergencies}

Good practice in public health should be appropriate, acceptable, cost-effective and equitable.

\section{Appropriateness}

In terms of public health, appropriate action produces health gain for the population concerned. The most appropriate action is the one that maximises health gain with the resources available. Initial assessment and subsequent monitoring of an emergency contain three components:

1. the health and nutritional status of the population.

2. the local resource capacity.

3. the additional requirements to deal with the problem.

\section{Acceptability}

An approach is acceptable if it ensures a good outcome, which is wanted by the beneficiaries. If a public health intervention is not acceptable to the population, it will fail. For example, chlorinating buckets of water taken from a contaminated source, is a technically adequate method to disinfect it. In some situations, this has been found to create problems, because people became convinced that they would be poisoned. ${ }^{8}$ It may be worthwhile to define emergency scenarios (e.g. small camps, large camps, and displaced people not in camps, besieged static populations) and try to determine the most effective and acceptable way to deal with each scenario. This categorisation could offer a method to refine standard approaches. In economic terms, utility would be emphasised more than efficacy (utility is what individuals want to maximise, the economic equivalent of happiness or satisfaction; 9 efficacy, in terms of health interventions, is the measured value under controlled test conditions).

\section{Cost-Effectiveness}

Programme cost calculated as an average cost per beneficiary can mask an extremely high marginal cost (the marginal cost at any level of output is the additional cost required to move one unit higher on the output scale)..$^{10}$ Programme decisions should take the marginal cost into account but keep in mind equity of access. While vaccination against measles is a cost-effective intervention at the individual level, for public health purposes one should also define the marginal cost at different levels of coverage under different conditions and determine the incremental cost-effectiveness ratio (ICER). Health gains would be maximised at a coverage level where the incremental cost of vaccination would no longer be proportional to the incremental gain in herd immunity. Decision-making and programme monitoring could benefit from research to determine the marginal cost of different activities.

\section{Equity}

The definition of equity is a matter of ongoing debate. In practice, the notion of equal access to health care for equal need can be used as a starting point. Where refugees or internally displaced persons are dispersed among a static population and use the same services, accepting the additional cost of providing free care to the entire population maybe the mostefficient way to provide equity of access to health services in an acute emergency. An increase in total cost is justified if it improves the effective provision of humanitarian aid.

Conflicts can occur between cost-effectiveness and equity of distribution. Before using this argument against the health economics approach, it should be clear that the awareness of conflicting needs is a result of information analysis. An informed decision will take the equity of service provision into account, and promote cost-effective ways to reach this goal.

In an emergency-affected population, some individuals and groups are more vulnerable, (e.g. one-parent households, unaccompanied minors, and aged persons with no family). Setting up protective mechanisms requires sensitive methods to identify them, and a non-discriminative approach to protection. If the former cannot be done in a cost-effective way, programmedesign could include a safety net. For example, 
it is common practice to offer supplementary food rations to all pregnant women, as there are no easy, reliable methods to detect those most at risk of malnutrition.

\section{Characteristics of Health Care Systems in Emergencies}

The management of emergency situations has been reshaped by conceptual changes. In recent years, many complex emergencies (e.g. Angola, Liberia, Somalia) have fluctuated between phases, with episodes of relative peace and stability, interrupted by recurring violence or socio-economic trouble. Theresponse to emergencies should recognise these fluctuations by taking a developmentbased approach at the earliest possible stage. Yet the notion of development in emergencies implies that the epidemiological situation is sufficiently under control to go beyond the short-term focus of containing avoidable deaths.

The expressions "early phase" or "acute phase" are sometimes used to describe the initial situation of excess mortality and morbidity beyond a defined threshold. The usual structures of primary health care do not yet or no longer exist, or are unable to cope with the type and amount of problems at hand. This phase will end when the epidemiological profile of the affected population has reversed to pre-crisis standards. Both needs and management methods will then resemble what is known tobe acceptable for the affected population at that time and place.

In "Refugee Health - an approach to emergency situations"," Médecins Sans Frontières have established ten top priorities. ${ }^{12}$ The initial provision of humanitarian assistance, including health care in acute emergencies could be improved by developing refinements to the standard approach, through the inclusion of certain situation indicators, asmentioned previously. After the first rapid assessment, adjustments should bemadeto address specific problems, taking local resources into account.

Even in countries at war, the emergency situation does not equally affect everybody. Pre-existing disparities in wealth and access to care will often remain in place. If the national health care system reflects these inequities, it will not be easy, and perhaps impossible to switch from high-tech priorities to a focus on primary health care. The situation can be worsened if inappropriate technology is imported to deal with the immediate problems.

In humanitarian emergencies, health care is often provided free of charge. Complex emergencies often occur in low-income countries, or in countries at war, settings where health insurance is either unknown or no longer operational. Long-term financing of health care will have to be (re-)considered as soon as the acute emergency is over. The management of the early phase of an emergency should be distinguished, but not completely separated, from the following phases (stabilisation, transition, return to development). Health economics can provide ways to assess national capacity to allocate resources to the health sector in the transition phase. Long-term substitution of national resources through external aid can be damaging, as can early withdrawal of external relief from an emergency affected population.

The choice of methods to provide relief in the early phase should facilitate the transition process towards renewed development. Where health care facilities and personnel remain functional, they should be strengthened and supported. Creation of new facilities should be in line with the existing structures, anticipating future needs. Introducing services that are more advanced than what is commonly expected will raise problems of sustainability, especially if they respond to a real need and are likely to create a demand (an examplecould be the acceptance of patients for elective surgery in an emergency unit).

\section{Conclusion}

There is often uncertainty over the preferred way to organise cost-effective, appropriate, acceptable emergency humanitarian action. In the early phase, a rapid needs assessment may only provide approximate data on the numbers of people affected, and the type and ex- tent of assistance required. Once a situation has stabilised, the long-term evolution of a complex crisis environment cannot be foreseen. Interventions that work in one setting might not be applicable or ineffective in another.

Reducing the margin of uncertainty can improve the provision of health care. In developed countries, healtheconomics is commonly used in the planning and management of health care. The same is true for health sector planning in stable developmental settings. Tools that are of proven value in these settings should be tested and developed for use in emergencies. Steps to achieve this goal consist of systematically identifying, quantifying and valuing inputs, together with epidemiological surveillance based on an initial needs assessment. These can be complemented with other methods of data collection according to necessity and feasibility. Case studies in different settings, examining all phases of an emergency, will be useful to build up a body of knowledge for planning, decision making and evaluation.

The management of an emergency situation should aim at technical efficiency, acceptability and cost-effectiveness. A toolkit for the application of health economics principles in emergencies could contain basic methods to calculate the cost of interventions under field conditions, as well as budget planning tools for affected governments and advanced modelling techniques for decision making at the donor level.

Until now, few agencies have calculated and compared the cost-effectiveness of single interventions, such as mass vaccination. The results show that information on cost and effectiveness can be collected and analysed to guide decision making, even in emergencies. If these efforts are carried out in a more systematic way, abody of evidence can be assembled for use in the early planning stage. Budget planning and cost evaluation of humanitarian programmes should gradually become part of emergency management, along with the development of indicators of programme effectiveness. 


\section{Acknowledgement}

With thanks to Charles Normand, Professor of Health Policy at the London School of Hygiene and Tropical Medicine for his supportive comments.

\section{Notes}

1. Kobelt, G. Health economics: an introduction to economic evaluation. London Office of Health Economics; 1996.

2. Roberts, L. and M. Toole. Cholera deaths in Goma. Lancet 346 (8987):1431; 1995.

3. Eono, P. et al. Burundi Humanitarian Mission (January-April 1994). Médecine Tropicale 55 (2) 172-7; 1995.

4. CopenhagenSteering Committee of the Joint evaluation of Emergency Assistance to Rwanda, Humanitarian aid and effects. The international response to conflict and genocide: lessons from the Rwanda experience: joint evaluation of emergency assistance to Rwanda; (3):111-118, 1996.

5. Naficy, A.et al. Treatment and vaccination strategies to control cholera in Sub-Saharan refugee settings. A cost-effectiveness analysis. Journal of the American Medical Association 279 (7): 521-525, 1998.

6. Veeken, H., K. Ritmeijer, and B. Hausman. Priority during a meningitis epidemic: vaccination or treatment? Bulletin of the World Health Organization 76 (2): 135-41, 1998.

7.Mills, A. and L.Gilson. Healtheconomics for developing countries: a survival kit. Evaluation and Planning Centre for Health Care, Publication Number 17, London School of Hygiene and Tropical Medicine; 1988. p. 51.

8. A rumour heard among the population in Mugunga camp in July 1994, implying that aid workers were trying to poison the Hutu refugees as a punishment for the massacre in Kigali in April 1994 (personal observation).

9. Mooney, G. Introduction Key issues in Health Economics; 1994.

10. Jacobs, P. The economics of health and medical care. Aspen Publishers; 1991 p. 128.

11. Médecinssans Frontières, Refugee Health, An approach to emergency situations. 1997. p. 38.

12. The ten top priorities, according to MSF are: Initial assessment, measles immunisation, water and sanitation, food and nutrition, shelter and site planning, health care in the emergency phase, control of communicable diseases and epidemics, public health. surveillance, human resources and training, co-ordination. $\square$

\section{Back Issues of Refuge, Canada's Periodical on Refugees}

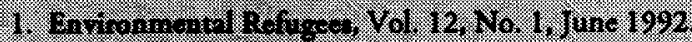

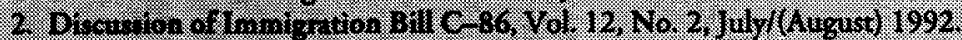

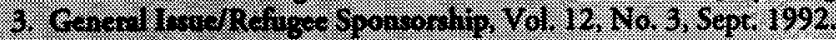

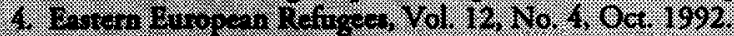

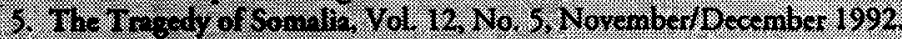

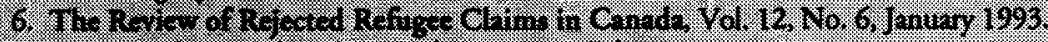

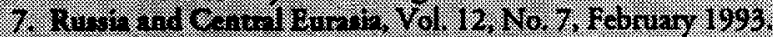

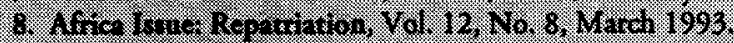

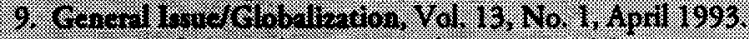

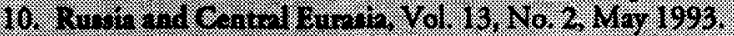

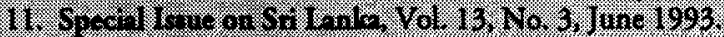

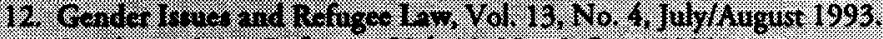

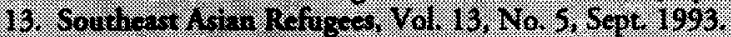

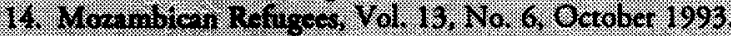

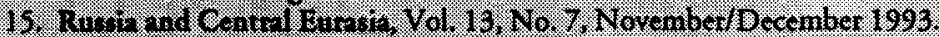

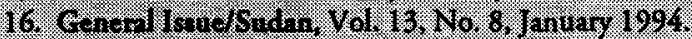

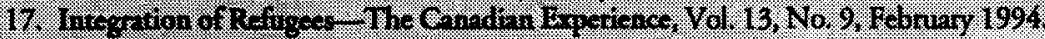

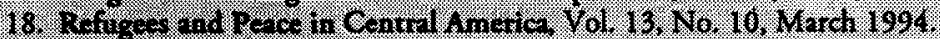

19. Horn of Africa. Vol. 14. No. 1. April 1994.

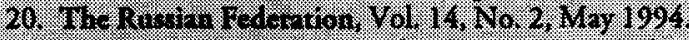

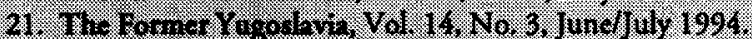

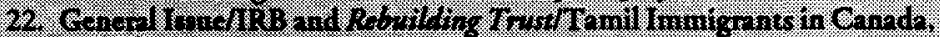

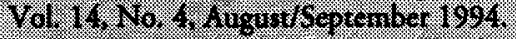

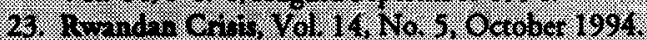

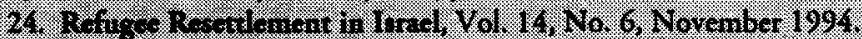

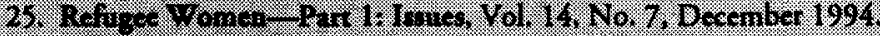

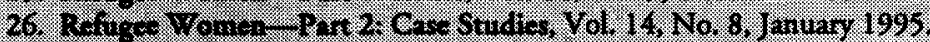

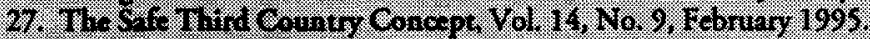

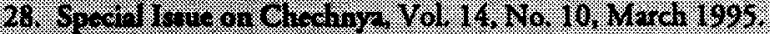

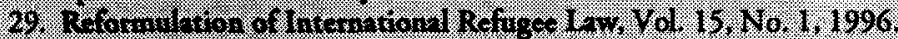

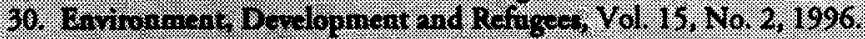

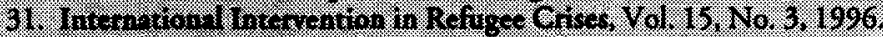

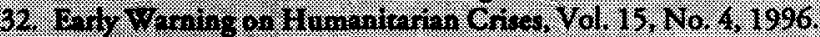

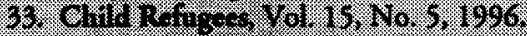

34. Gibbal Sariemont Sorrice Vol: 15. No. 6. 1997

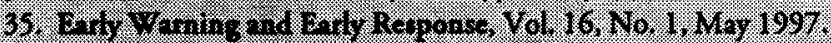

36. Uprooking and Conequiencer, Vol. 16, No. 2, June 1997.

37.02 .010 .

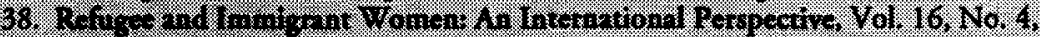
C.r. $3.0 .19 \%$

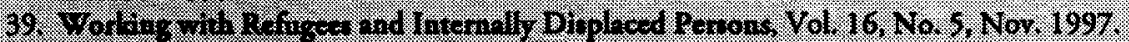

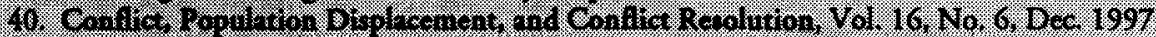

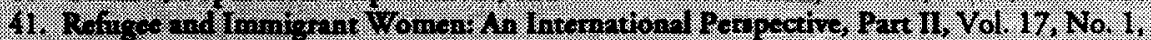
106.

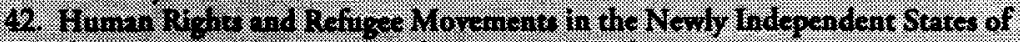

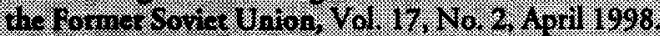

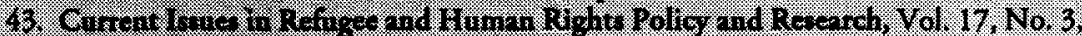
Augis: 1998

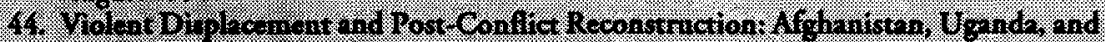

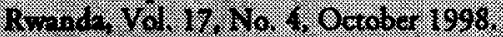

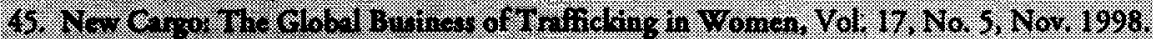

46. Cenivol Rer.

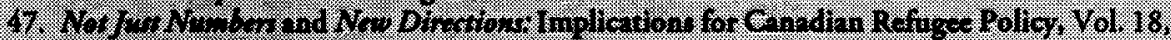

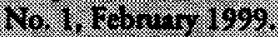

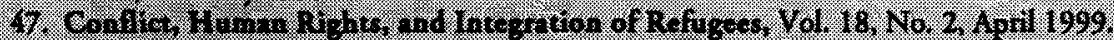

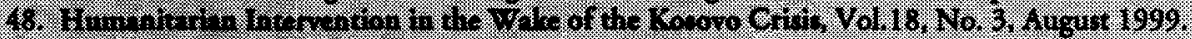

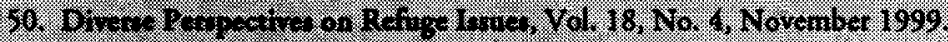

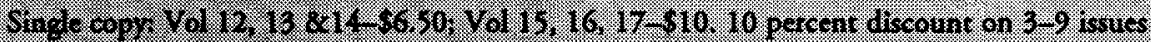

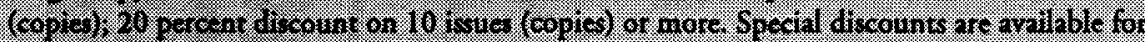

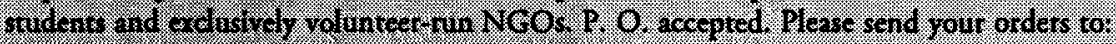

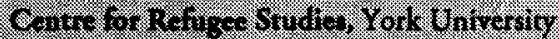

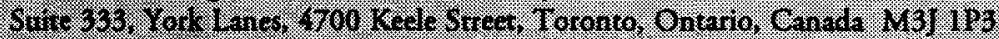

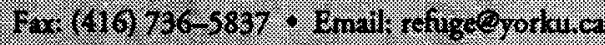

